\title{
Indústria de Alta Tecnologia: uma tipologia baseada na intensidade de P\&D e no desempenho comercial*
}

\author{
André Tortato Rauen** \\ André Tosi Furtado***
}

\section{RESUMO}

Este artigo tem por objetivo construir e discutir uma tipologia de indústrias nacionais de alta tecnologia fundamentada na intensidade tecnológica e no desempenho comercial. Para tanto, apoia-se no conceito de fragmentação da produção, contrastando-o com teorias tradicionais de comércio internacional. Para definir a posição das diferentes economias, optou-se por uma análise matricial que cruza indicadores compostos selecionados, resultando numa análise de quadrantes. Essa análise encontrou quadro grupos de países: líderes tecnológicos superavitários; líderes tecnológicos deficitários; seguidores tecnológicos superavitários; e seguidores tecnológicos deficitários. Concluiu-se que as teorias tradicionais de comércio internacional explicam apenas parte desta tipologia e que uma compreensão mais completa, obrigatoriamente, precisa considerar a fragmentação da produção enquanto lógica dominante das cadeias produtivas globais.

* Os autores agradecem ao Conselho Nacional de Desenvolvimento Científico e Tecnológico - CNPq pelo financiamento à pesquisa que culminou nesse artigo.

** Tecnologista Pleno, Ministério da Ciência, Tecnologia e Inovação, Brasília (DF), Brasil. E-mail: andrerauen@gmail.com

*** Professor do Departamento de Política Científica e Tecnológica, Universidade Estadual de Campinas (UNICAMP), Campinas (SP), Brasil. E-mail: furtado@ige.unicamp.br 
Palavras-Chave | Alta Tecnologia; Fragmentação da Produção; Comércio Exterior

Código JEL | O14; F23; F14

High-tech industry: a taxonomy based on R\&D intensity and trade performance

\section{ABSTRACT}

This paper aims to build and discuss a typology of national high tech industries according to technology intensity and international trade. To fundament the analyze it was used the production fragmentation concept. It was made a matrix of countries according to their position in the two selected indicators. As a result it was found four types of countries: (i) surplus technology leaders; (ii) deficit technology leaders; (iii) surplus technology followers and (iv) deficit technology followers. The paper concludes that the traditional theories about international commerce cannot explain the matrix as a whole. To do so, it is necessary to use the production fragmentation concept that is a new concept in the global value chain theory.

KEYWORDS | High Technology; Product fragmentation; Foreign Trade

JEL CODE | O14; F23; F14

\section{Introdução}

Mesmo que a mudança técnica seja levada em conta pelas formulações mais difundidas na literatura sobre o comércio internacional (RICARDO, 1817; OHLIN, 1933; PORTER, 1986; KRUGMAN, 1991), o primeiro trabalho de fôlego a colocá-la no centro da análise, por meio da síntese de argumentos neoschumpeterianos, foi realizado por Giovanni Dosi, Keith Pavitt e Luc Soete em 1990 e intitulado The economics of technical change and international trade. Nessa teorização, que pode ser chamada de evolucionária, mas que muito se alimenta da teoria do ciclo de vida do produto elaborada por Vernon (1966), Hirsch (1967) e Wells (1968), diferenças nas taxas e direção da mudança técnica explicariam a divisão internacional do trabalho. No que tange ao comércio de alta tecnologia, a relevância da mudança técnica seria ainda maior, uma vez que dela dependeria a própria existência desta indústria. 
De forma um tanto geral, a divisão internacional do trabalho proposta pelos evolucionários separara os países em dois grandes grupos: líderes tecnológicos; e seguidores tecnológicos. Considerando-se o comércio internacional de alta tecnologia, países líderes tenderiam a ser superavitários, enquanto os seguidores seriam deficitários. De fato, no trabalho de Dosi, Pavitt e Soete (1990), fica implícita a ideia de que, quanto maior a intensidade tecnológica, maior é o saldo comercial (especificamente para a alta tecnologia). $\mathrm{O}$ argumento subjacente, então, é de que os fluxos de comércio dependem da tecnologia.

Nesse mesmo sentido, a própria teoria do ciclo de vida do produto pressupóe a existência de países líderes tecnológicos (exportadores líquidos de produtos tecnologicamente complexos) e países seguidores (importadores líquidos de produtos complexos).

Os trabalhos de Vernon (1966), Hirsch (1967), Wells (1968) e Dosi, Pavitt e Soete (1990), apesar de avançarem na compreensão da relação entre capacitação tecnológica nacional e inserção comercial, precisam ser revistos à luz da variada gama de transformaçôes recentes da economia capitalista, em especial aquelas que alteraram a organização das cadeias produtivas de alta tecnologia. Como se verá, estas transformaçóes incluem, entre outros aspectos, o descolamento espacial entre a produção física de um bem e sua concepção e desenvolvimento. Como consequência, a relação direta que existia entre intensidade tecnológica e saldo comercial diminui significativamente.

Considerando-se a indústria de alta tecnologia - em que as transformações recentes são mais evidentes - e em face das radicais transformações ocorridas na coordenação das cadeias produtivas globais, o objetivo deste trabalho é analisar em que medida se modificaram as relações entre tecnologia e comércio exterior descritas, por exemplo, por Vernon (1966), Hircsh (1967), Wells (1968) e Dosi, Pavitt e Soete (1990). Nesse contexto, a partir da análise das diferenças nas intensidades tecnológicas, este artigo propõe uma nova tipologia de países em função das intensidades tecnológicas médias e dos saldos comerciais dos setores classificados como de alta tecnologia. A tipologia aqui proposta é resultante da interação entre geração de conhecimento e fragmentação da produção.

Além desta introdução, o trabalho conta com três outras seções. A seguir, discutem-se as transformações recentes na forma de organizar as cadeias produtivas globais de alta tecnologia. Posteriormente, é apresentada a metodologia utilizada na análise da moderna divisão internacional do trabalho. Por fim, discute-se a tipologia resultante da análise aqui proposta, enfatizando dois novos grupos de países. 


\section{Novas configurações espaciais: a fragmentação da produção da alta tecnologia}

Mesmo que o entendimento da relevância da alta tecnologia para o conjunto da economia e da indústria não seja unânime, ${ }^{1}$ existe certa preponderância de estudos, principalmente de organismos internacionais, que a consideram fundamental ao processo de capacitação tecnológica nacional.

Soma-se a este controverso cenário o fato de que as recentes transformações globalizantes tornaram confusa e incerta a determinação da dinâmica de localização destas atividades, principalmente quando se tenta identificá-la com o uso de abordagens tradicionais da geografia econômica. Nessas discussóes mais tradicionais, o mercado consumidor e a fonte de matérias-primas formam o espectro de possibilidades da localização, o que, de forma nenhuma, contempla a possibilidade de produção dispersa e segmentada.

Habitualmente, atividades industriais de alta tecnologia encontravam-se localizadas apenas em países desenvolvidos de elevada renda per capita. Contudo, as transformações econômicas, sociais e políticas que se iniciaram em meados da década de 1970, e que estão associadas com o fim da era de ouro do capitalismo (HOBSBAWM, 1995), redefiniram a geografia econômica mundial. A abertura de economias antes fechadas ao capital internacional e a revolução tecnológica que se insere nestas transformações alargaram as possibilidades de localização das unidades fabris (CASTELLS, 1999). Antes restrita à tríade Estados Unidos, Europa e Japão, a decisão locacional da firma industrial de alta tecnologia agora é muito mais difusa e complexa (ERNST; KIM, 2002). Nesse contexto, a simples divisão entre norte e sul não é mais suficiente para compreender os fluxos de comércio internacional ou mesmo a geografia industrial contemporânea.

Muito embora os centros dinâmicos permaneçam como os principais mercados consumidores, estatísticas de comércio exterior demonstram que existe uma intensa atividade industrial mesmo na periferia do sistema. Estas estatísticas mostram ainda que os produtos de alta tecnologia são justamente os de crescimento mais acelerado no atual comércio internacional (SRHOLEC, 2007). De fato, como poderá ser observado neste trabalho, houve uma grande dispersão da produção.

Tal como mostra Chesnais (1996), o aprofundamento da dinâmica de abertura econômica - que levou, com raras exceções e ao contrário do que postula a escola

1 Ver, por exemplo, Nelson e Rosenberg (1993), Smith (1999, 2000), Hirsch-Kreisen et al. (2003) e Hirsch-Kreisen (2008). 
ortodoxa do comércio exterior, ao recrudescimento das desigualdades tecnológicas entre os países - talvez seja a característica mais marcante da atual geografia das indústrias de alta tecnologia. Ou seja, a geografia industrial norte e sul, que existiu durante toda a primeira metade do século XX, foi substituída por uma muito mais complexa, na qual novos centros industriais surgem e antigos perdem relevância.

Nesse contexto, o atual panorama do comércio internacional mostra um quadro um tanto diferente daquele observado no passado recente, principalmente quando se consideram os pressupostos da teoria do ciclo de vida do produto, elaborada pioneiramente por Raymond Vernon. ${ }^{2}$ Estatísticas oficiais (principalmente baseadas em dados do Comtrade) mostram que países como Coreia, China, Cingapura e Tailândia, entre outros emergentes, são importantes exportadores de produtos classificados como de alta tecnologia. É verdade que boa parte das exportaçôes de produtos tecnologicamente complexos ainda é feita por países desenvolvidos, contudo, pela primeira vez na história recente do sistema capitalista, países em desenvolvimento estão exportando produtos tipificados como de alta tecnologia.

As razões para essa nova geografia econômica da produção de alta tecnologia residem na recente possibilidade de separar espacialmente e por etapas a cadeia de valor de um mesmo produto de alta tecnologia. Três elementos históricos permitiram esta dispersão espacial e organizacional da produção: novas estratégias empresarias de internacionalização e desverticalização; convergência tecnológica de parte da antiga periferia; e inovaçôes tecnológicas e organizacionais nos campos da logística e da informação.

O fim da era de ouro do capitalismo, ocorrido em meados dos anos 1970, causou uma robusta crise econômica, principalmente no centro do sistema, que só pôde ser superada em razão de novas estratégias empresariais baseadas no intenso uso das tecnologias de informação e comunicação, na globalização das atividades industriais e na desverticalização da produção. Portanto, como saída para essa crise de acumulação do capital, grandes firmas multinacionais de países desenvolvidos

2 Em artigo intitulado "International investment and international trade product cycle", publicado na Quartely Journal of Economics, em maio de 1966, Raymond Vernon apresentou um elegante modelo que objetivava compreender porque novos produtos ou inovaçôes tendem a surgir primeiro em países ricos de altos salários médios. O modelo foi construído com base na experiência estadunidense de comércio exterior e nas de seus principais parceiros comerciais. O artigo de Vernon (1966) foi a base para o também seminal trabalho de Wells (1968), este publicado no Journal of Marketing, em julho de 1968, e intitulado "A product life cycle for international trade?” De forma geral, os autores afirmavam que novos produtos de alta elasticidade renda da demanda tendem a surgir primeiro em países ricos de altos salários médios, pois neles existem tanto a demanda por estes produtos quanto as condiçôes para que eles sejam produzidos. Para os autores, o deslocamento espacial da produção destes bens dependeria da fase de padronização da produção. Nesse sentido, apenas bens com alto nível de padronização poderiam ser produzidos em países de baixa renda per capita. 
procuraram alargar suas possibilidades, explorando diferenças internacionais nos custos de produção. ${ }^{3}$

Por outro lado, a convergência tecnológica de parte da antiga periferia, notadamente asiática, permitiu vazão às estratégias de produção internacionalizadas de grandes firmas multinacionais de países desenvolvidos. Alguns países da antiga periferia, por possuírem baixo custo de produção e alguma capacidade tecnológica, acabaram exercendo forte poder de atração de atividades de manufatura e montagem final. Já a crescente demanda interna destes países, tal como afirmam Macher e Mowery (2008), também foi relevante e, por isso, deve ser considerada na análise da reorganização espacial da produção de alta tecnologia.

Finalmente, um conjunto de inovaçōes nos campos da informação e comunicação possibilitou a coordenação facilitada do processo produtivo, mesmo quando este é executado em diversos países geograficamente distantes. De fato, como se verá mais adiante, as redes globais só se estabelecem em razão da criação protocolos comuns e da automação do processo produtivo moderno (STURGEON, 2002).

Assim, a firma, ao enfrentar situação adversa associada ao recrudescimento dos níveis de concorrência, se desonera de seus ativos menos críticos e se concentra naqueles associados às suas competências centrais. Empresas detentoras de marcas reconhecidas em setores de alta tecnologia acabam por se especializar em design e desenvolvimento de novos produtos, deixando para outras empresas, ou algumas vezes para outras divisões do mesmo grupo, as atividades de manufatura, que são menos críticas. Por outro lado, empresas cujas competências centrais estão associadas ao processo produtivo, com pouco reconhecimento de marca nos mercados finais, acabam por se concentrar na manufatura.

Do ponto de vista das firmas líderes nas cadeias de produção, a desverticalização, que ocorreu em concomitância com a globalização das relações econômicas, permitiu a redução de riscos produtivos e, principalmente, o aumento do escopo de atuação, tanto de sua produção quanto de sua oferta de produtos. É importante ressaltar, nesse contexto, que a desverticalização em setores de alta tecnologia tende a ser maior do que naqueles tradicionais, uma vez que a complexidade dos produtos e o vasto número de componentes empregados na produção tornam virtualmente impossível a uma única empresa produzir sozinha todos os componentes de um produto de alta tecnologia.

3 Por custos de produção entendem-se todas as condições sistémicas inerentes a um dado país que influenciem direta ou indiretamente a formação dos custos finais de manufatura. Ou seja, consideram-se questôes referentes a câmbio, crédito, infraestrutura, sindicatos, meio ambiente e, finalmente, mão de obra. 
A fragmentação da produção, que emerge desse contexto histórico particular, pode ser entendida como a divisão espacial das etapas de manufatura entre países e, mesmo que a estratégia de produção fragmentada não exija subcontratação, para Sturgeon (2002), o processo produtivo modular (via subcontratação) é a forma mais economicamente eficiente de se produzir sob o paradigma da produção fragmentada. A produção modular caracteriza-se pela alta desverticalização das empresas com forte concentração das atividades nas áreas de maior eficiência.

Portanto, a fragmentação da produção diz respeito à separação espacial das diferentes etapas de manufatura, quase sempre com separação do controle de capital, que ocorre em razão do esgotamento do padrão de acumulação fundado na grande firma verticalizada e espacialmente enraizada. Nesse sentido, a fragmentação é o resultado de um processo produtivo modularizado e global. Para Ernst e Kim (2002, p. 01), "as cadeias globais de produção são uma das maiores inovações na organização dos negócios internacionais”.

A fragmentação é um movimento que se inicia nos países desenvolvidos e gradualmente passa a incorporar alguns países em desenvolvimento de baixos salários. Nessa dinâmica, primeiro se dispersa a produção e, só num segundo momento, o consumo. De fato, a própria fragmentação da produção, ao levar à diminuição de preços, por meio da otimização dos processos associada ao aumento de renda per capita de alguns países em desenvolvimento, permitiu o incremento do consumo destes em setores de alta tecnologia. Mesmo assim, o movimento central é o de dispersão espacial da produção que se destina, sobretudo, aos mercados de países desenvolvidos.

Uma cadeia de valor modularizada típica possui uma grande empresa com marca reconhecida no mercado, com sede em um país desenvolvido, que se concentra no desenvolvimento de novos produtos e atualizaçōes. Ernst e Kim (2002) chamam este tipo de "líderes de marca". Suas atividades exigem forte investimento em $\mathrm{P} \& \mathrm{D}$ direcionado para a criação de inovações de produto, bem como mão de obra qualificada. Por outro lado, existe uma série de empresas dedicadas à manufatura, servindo, quase sempre sem exclusividade, a essa grande empresa detentora de marca reconhecida.

Do ponto de vista produtivo, esta cadeia de valor é composta, então, por uma série de etapas. De forma um tanto geral, a produção de bens de alta tecnologia inicia-se com o conceito e o planejamento do produto, na sequência têm-se a revisão do design, a prototipagem e a produção piloto, numa terceira etapa, de forma simultânea, tem-se a manufatura da plataforma e dos componentes que irão ser 
inseridos nesta plataforma. Os componentes são, então, montados na plataforma e o produto segue para distribuição e consumo final.

Uma cadeia fragmentada que serve a um mercado consumidor de alta renda possui as atividades iniciais (conceito e planejamento do produto) e as finais (de venda) geograficamente próximas do mercado. Por outro lado, as atividades de design, prototipagem e produção piloto, bem como de manufatura da plataforma dos componentes e montagem, tendem a estar localizadas em países de baixos salários médios e, portanto, geograficamente distantes do mercado consumidor (DEDRICK; KRAEMER, 2008).

Em interessante estudo que visa compreender os diferentes graus de apropriabilidade econômica ${ }^{4}$ em uma dada cadeia produtiva fragmentada de um artefato de alta tecnologia, Linden, Kraemer e Dedrick (2007) mostram que as firmas detentoras de marca, apesar de se concentrarem em poucas etapas do processo produtivo, são as que mais se apropriam das receitas geradas pelo produto.

Por outro lado, estas firmas dependem de uma intrincada rede internacional de subcontratados. Nestas redes existe forte integração e circulação de informações. Mesmo assim, as relações que podem ser rapidamente estabelecidas são também muito flexíveis, tal como aquelas associadas a relaçôes puramente de mercado descritas, por exemplo, por Humphrey e Schmitz (2002).

Estas redes só se estabelecem em função da existência de padrões e protocolos amplamente difundidos, os quais se encontram associados à grande automatização dos processos produtivos. De fato, essa grande automatização vem substituindo, pelo menos em parte, a necessidade de relacionamentos derivados de inúmeras transações feitas ao longo de grandes períodos de tempo (STURGEON, 2002). É importante ressaltar que a produção fragmentada de maneira nenhuma pressupõe estabelecimento de quase-hierarquias entre a contratante e a contratada. A coordenação das cadeias dependerá da estrutura de mercado e, principalmente, da base tecnológica na qual se apoia a produção. Ou seja, as redes que se estabelecem no contexto de uma produção fragmentada são de uma enorme variedade, principalmente quando se observam as formas de governança.

Tal como apresenta Zeitoum (2009), o esforço tecnológico das firmas subcontratadas pode levar a intensos processos de reorganização da cadeia e permitir que estas alterem em seu favor as relações de poder (as quais também se tornam flagships, isto é, empresas que coordenam redes e acessam as diferentes capacidades

4 Apropriabilidade pode ser definida como a capacidade de uma firma, instituição ou indivíduo de se apropriar dos retornos financeiros de uma inovação. Geralmente, fala-se em termos de graus de apropriabilidade. 
destas redes). Assim, mesmo que a firma subcontratada se coloque inicialmente como incorporadora líquida de tecnologia e ocupe uma posição de baixa agregação relativa de valor, essa posição não é de forma alguma estática. $\mathrm{O}$ posicionamento da firma na cadeia produtiva e seu poder de barganha dependem das estratégias individuais, principalmente de seu esforço tecnológico.

Por ocorrer em razão de diferenças internacionais nas vantagens competitivas, a possibilidade de fragmentar a produção leva a uma certa divisão internacional do trabalho. De forma geral, nessa divisão, países desenvolvidos, em razão de economias de escala, escopo e aglomeração, se especializam em etapas tecnologicamente mais nobres da cadeia de valor, enquanto países em desenvolvimento, por apresentarem salários e demais custos de produção relativamente mais baixos, acabam se especializando em etapas menos complexas e de maior intensidade de mão de obra.

Contudo, este é apenas o movimento geral. Mesmo que as forças de fragmentação tendam a deslocar a produção dos países desenvolvidos de altos salários para países em desenvolvimento de baixos salários, outros elementos, como políticas públicas relacionadas à manutenção do emprego e à especialização produtiva nacional, podem arrefecer estas tendências e evitar, pelo menos em parte, essa dispersão espacial da produção.

Entretanto, a recepção de atividades fragmentadas de produção não pode ocorrer em qualquer tipo de país de baixo salário. Sua atração depende de políticas industriais específicas, da presença de economias de aglomeração e, inclusive, de mercados consumidores locais. De forma geral, a posição de cada país nas cadeias de valor da alta tecnologia dependerá, então, do nível tecnológico deste e da eficácia das políticas industriais executadas.

Por outro lado, a posição de cada país nas cadeias de valor nada diz sobre seu desempenho comercial. Se ao nível da firma, tal como mostram Linden, Kraemer e Dedrick (2007), as decisões de deslocar a produção garantem maior apropriação dos lucros, ao nível do país o deslocamento da produção pode gerar volumosa saída líquida de capitais, mesmo que as etapas executadas neste país sejam as de maior complexidade tecnológica.

Como resultado deste novo contexto produtivo, tem-se uma divisão internacional do trabalho um tanto diferente daquela amplamente conhecida e apresentada por Vernon (1966), Hircsh (1967), Wells (1968) e Dosi, Pavitt e Soete (1990). Se, para estes autores, existe uma correlação positiva entre o desenvolvimento tecnológico nacional e o saldo comercial de alta tecnologia, este não parece ser o caso aqui observado. 


\section{Metodologia}

Para a OCDE (2007), os setores de alta tecnologia - aeroespacial, farmacêutico, informática, equipamentos eletrônicos e de comunicação e instrumentação de precisão - são aqueles nos quais os gastos internos em $\mathrm{P} \& \mathrm{D}$ em relação tanto ao valor bruto da produção quanto ao valor da transformação industrial são significativamente maiores do que a média de todos os setores.

Apesar das críticas feitas sobre o uso da P\&D como indicador de esforço tecnológico (HIRSCH-KREINSEN et al., 2003; FREEMAN; SOETE, 2008), entre os indicadores atualmente disponíveis para a indústria de alta tecnologia, ela representa com certa precisão o grau de complexidade tecnológica da produção, uma vez que, em razão das altas oportunidades tecnológicas desta indústria, o esforço de mudança técnica é, em boa medida, dependente de esforços formais e internos de pesquisa e desenvolvimento. Pavitt (1984), por exemplo, afirma que as fontes de informação para a mudança técnica na indústria de alta tecnologia estão associadas a conhecimentos científicos fortemente apoiados em esforços internos de P\&D.

Num contexto de produção fragmentada, as diferenças nas intensidades tecnológicas mostram, então, a forma pela qual se dividem os países produtores de alta tecnologia. Dessa forma, o cruzamento entre intensidades e saldos comerciais permite compreender como se relacionam a geração de conhecimento no processo produtivo e a competitividade internacional desta produção. A tese atualmente difundida, tanto pela ortodoxia quanto pela heterodoxia econômica, é a de que existe forte correlação positiva entre competitividade internacional (medida, por exemplo, pelas exportações) e geração de conhecimento expressa pela mudança técnica.

Nesse sentido, considerando-se a visão mais tradicional do comércio exterior, saldos comerciais positivos em alta tecnologia tendem a se apoiar em altas intensidades tecnológicas. Ou seja, ao longo do século XX, observou-se uma correlação positiva entre intensidade tecnológica e superávit comercial, contudo, postula-se aqui que as profundas mudanças na forma de organizar as cadeias produtivas influenciaram esta correlação.

Diante do exposto, quando os gastos internos em P\&D em setores de alta tecnologia são observados em relação à produção, tem-se uma aproximação da geração de conhecimento incorporada no produto. Não se trata apenas, portanto, de uma proxy da complexidade da produção, mas sim de uma proxy da criação de conhecimento realizada em função da produção. A utilização deste indicador, tal como aqui se propõe, permite analisar as diferenças internacionais em termos 
de agregação de conhecimento no variado conjunto de processos produtivos que compõem as cadeias de produção da alta tecnologia.

Atualmente, encontra-se disponível um bom número de indicadores de ciência e tecnologia, tais como taxa de inovação, artigos, patentes, pedidos de patentes, etc. Contudo, em se tratando da indústria de alta tecnologia, o mais relevante é aquele que mensura os gastos em pesquisa e desenvolvimento, uma vez que a própria definição de alta tecnologia depende da existência de tais gastos. Ou seja, a inovação em tais setores depende fundamentalmente da existência de esforços formais de pesquisa e desenvolvimento. Portanto, para analisar a geração da tecnologia, escolheu-se também o indicador mais consagrado para tanto, a intensidade de P\&D.

Mesmo que estatísticas oficiais tenham avançado muito ao longo da última década (basta observar o número de bases de dados internacionais disponíveis na web e a profusão de manuais elaborados pela OCDE), a forma de coleta e tratamento de dados e indicadores ainda difere muito entre os países. A necessidade de utilizar séries históricas envolvendo economias com níveis de desenvolvimento distintos torna esse já complicado processo de comparação internacional ainda mais difícil, limitando, portanto, o escopo da análise. Por estes motivos, a metodologia escolhida é um tanto simples, trata-se de uma analise matricial do tipo $2 \mathrm{X} 2$.

Por outro lado, o método escolhido, matricial, é adequado ao objetivo do trabalho: observar o comportamento da relação entre o desempenho comercial e a agregação de conhecimento na produção de bens de alta intensidade tecnológica. Do ponto de vista comercial, escolheu-se o indicador mais consagrado - o saldo comercial -, muito embora, tentando relativizá-lo, optou-se por apresentá-lo em termos percentuais do volume total transacionado pelo país num ano.

No esforço de análise empírica, foi preciso, primeiro, selecionar os países mais relevantes na produção mundial de alta tecnologia (tal como definida pela OCDE), pois, em razão do vasto número de participantes nas cadeias fragmentadas de valor, uma análise censitária tornar-se-ia inviável. Para realizar tal recorte, optou-se, em razão de sua ampla disponibilidade, por utilizar o Valor Bruto da Produção Industrial - VBP dos setores de alta tecnologia. Nesse sentido, foram ordenadas as principais indústrias de alta tecnologia com base nesse indicador calculado para o último ano disponível (2007) e deste ordenamento optou-se por analisar apenas as 16 primeiras economias. ${ }^{5}$ A escolha deste recorte deve-se ao fato de que depois da décima sexta economia a participação percentual na produção mundial deixa de

5 Dados mais recentes estão disponíveis para um pequeno conjunto de países, mas não para todas as 16 maiores indústrias de alta tecnologia do mundo. 
ser significativa (menor que $1 \%$ segundo os dados disponíveis), portanto, pouco contribuindo para a análise pretendida.

Como pode ser observado na Tabela 1, importantes economias emergentes não são analisadas, uma vez que ou não disponibilizam dados ou sua participação no total da indústria mundial não passa de $1 \%$. Nesse sentido, estão ausentes da análise Rússia, Índia, Malásia, economias do leste europeu, entre outras economias emergentes.

Uma vez selecionados os países, coube, num segundo momento, classificá-los de acordo com as categoriais propostas. Para tanto, tal como já mencionado, foram selecionados a intensidade tecnológica (P\&D/VBP), para determinação da geração de tecnologia, e o saldo comercial relativo, para determinação do desempenho comercial.

Objetivando conferir alguma dinamicidade na análise, foi observado o comportamento das 16 economias num período de três anos. Obviamente, um período maior seria desejável, contudo, a disponibilidade de dados internacionalmente comparáveis limita o escopo de observação. De todos os períodos recentes possíveis, apenas aquele que compreende os anos de 2005, 2006 e 2007 está disponível para o conjunto das economias. É verdade, porém, que períodos mais recentes estão disponíveis para uma ou outra econômica aqui analisada, mas não para todas. Consequentemente, tem-se uma análise historicamente circunscrita, que é consequência da dificuldade em encontrar dados confiáveis e internacionalmente comparáveis.

Nesse sentido, foram criados dois indicadores compostos: intensidade tecnológica média $(\mathrm{Im})$ e saldo comercial relativo médio $(\mathrm{Sm})$. A intensidade média, que segue as orientaçôes de cálculo da OCDE, pode ser descrita como:

$$
\operatorname{Im}_{\mathrm{i}}=\mu\left[\left(\frac{P_{j}^{i}}{V_{j}^{i}}\right) * 100\right]
$$

onde: $I m_{i}$ refere-se à intensidade média do país $i$ no período considerado; $\mu$ é a média dos três anos (2005, 2006 e 2007); $P_{j}^{i}$ corresponde ao gasto em P\&D dos setores de alta tecnologia do país $i$ no ano $j$; e $V_{j}^{i}$ é o valor bruto da produção industrial dos setores de alta tecnologia do país $i$ no ano $j$.

Por outro lado, o saldo comercial relativo é expresso como:

$$
S m_{\mathrm{i}}=\mu\left[\left(\frac{X_{j}^{i}-M_{j}^{i}}{X_{j}^{i}+M_{j}^{i}}\right) * 100\right]
$$


onde: $\mathrm{Sm}_{i}$ refere-se ao saldo comercial relativo ao volume total transacionado pelo país $i$ no período considerado; $\mu$ é a média dos três anos; $X_{j}^{i}$ corresponde à exportação do país $i$ no ano $j$; e $M_{j}^{i}$ é a importação do país $i$ no ano $j$.

Para explicar a dinâmica econômica inerente a cada grupo de países, além do uso de autores que tratam das cadeias produtivas fragmentadas, empregaram-se também contribuiçôes de autores que analisam historicamente a inserção internacional das principais economias do mundo. Sempre que possível, as contribuiçōes destes dois grupos de autores foram ilustradas e corroboradas por dados atuais variados. $\mathrm{Ou}$ seja, buscam-se na literatura e em dados secundários variados interpretaçôes para os fenômenos observados.

Com exceção de Brasil, México, China e Cingapura, para os quais foi necessária uma pesquisa nos institutos nacionais, para todos os outros países as informações foram extraídas da base de dados da OCDE (OECD.Stat.). No caso brasileiro, coletaram-se dados no Ministério da Indústria e Comércio Exterior (MDIC/Secex) e no Instituto Brasileiro de Geografia e Estatística (IBGE). Para o México, os dados são provenientes do Instituto Nacional de Geografia e Estatística (Inegi), para a indústria chinesa de alta tecnologia, do Ministério da Ciência e Tecnologia (MST) e, para a de Cingapura, do Departamento de Estatísticas (Singstat). Todos os indicadores são apresentados em dólares americanos e a conversão, quando exigida, foi realizada por meio de taxas de câmbios anuais disponibilizadas pela OECD.Stat (Tabela 1).

Depois de selecionados os 16 países, estes foram categorizados de acordo com os dois indicadores de classificação: intensidade de P\&D e saldo comercial. Para definir os países líderes, utilizou-se como parâmetro a mediana das intensidades tecnológicas do grupo. Assim, se $\operatorname{Im}_{i} \geq 6,8 \%$, então o país é considerado líder tecnológico, do contrário, seguidor tecnológico. Por outro lado, se $\mathrm{Sm}_{\mathrm{i}} \geq$ 0 , o país é considerado superavitário, caso contrário, deficitário. Como resultado obteve-se uma matriz $2 \mathrm{X} 2$.

Em que pese alguma arbitrariedade na seleção dos critérios de classificação, sua escolha deve-se à facilidade de compreensão. De fato, os critérios escolhidos são intuitivos, mas estão alinhados com a abordagem aqui defendida, qual seja, a de apresentar a mecânica geral e agregada de funcionamento de uma nova divisão do trabalho em setores de alta tecnologia. 
TABELA 1

Principais produtores mundiais de alta tecnologia, por indicadores selecionados da indústria de alta tecnologia (US\$ correntes e pessoal ocupado) - 2005-2007

\begin{tabular}{l|c|c|c}
\hline \multicolumn{1}{c|}{ Países } & $\begin{array}{c}\text { Valor bruto da } \\
\text { produçáo em 2007 } \\
\text { (US\$ bilhões) }\end{array}$ & $\begin{array}{c}\text { Intensidade } \\
\text { tecnológica média do } \\
\text { período } \\
\mathbf{2 0 0 5 - 2 0 0 7} \\
\text { (\% do VBP) }\end{array}$ & $\begin{array}{c}\text { Saldo comercial } \\
\text { relativo médio do } \\
\text { período 2005-2007 } \\
\text { (\% do volume } \\
\text { comercializado) }\end{array}$ \\
\hline Estados Unidos & 769,3 & 16,2 & $-29,4$ \\
China & 557,7 & 1,2 & 7,6 \\
Japão & 417,7 & 10,5 & 14,9 \\
Coreia & 263,3 & $5,7^{(2)}$ & 27,0 \\
Alemanha & 238,8 & 7,9 & 4,4 \\
França & 181,4 & 8,0 & 1,9 \\
México & $128,5^{(1)}$ & $0,2^{(1)}$ & 0,9 \\
Itália & 99,8 & 3,9 & $-1,9$ \\
Reino Unido & 99,6 & 11,2 & $-8,0$ \\
Cingapura & $81,5^{(1)}$ & $1,6^{(1)}$ & 19,8 \\
Irlanda & 56,1 & 1,4 & 18,8 \\
Brasil & 46,5 & $1,8^{(1)(4)}$ & $-38,0$ \\
Suécia & 43,9 & 12,7 & 13,3 \\
Espanha & 39,3 & 5,1 & $-20,9$ \\
Canadá & 39,0 & $11,2^{(3)}$ & $-22,5$ \\
Holanda & 30,2 & 9,0 & 3,0 \\
\hline
\end{tabular}

Fonte: OECD.Stat, IBGE, ECB, NBSC, MST, Inegi, Singstat, Comtrade.

Nota: Na ausência do setor aeroespacial, inclui "outros equipamentos de transporte".

VBP de 2007 do setor "aeroespacial" foi estimado.

VBP da alta tecnologia de 2007 foi estimado.

Dados referentes ao período de 2003, 2005 e 2008.

Cabe ressaltar que os dados referentes à indústria de alta tecnologia são analisados de forma agregada, constituindo-se no somatório dos cinco setores industriais classificados como de alta tecnologia pela OCDE. Notadamente, a utilização de dados desagregados poderia resultar em distintas tipologias para cada um dos setores, pois diferentes são os estímulos a serem fragmentados. ${ }^{6}$ A opção pela agregação ocorre em razão da necessidade de se compreender o movimento geral do comércio de produtos complexos e não de movimentos setoriais específicos.

Na próxima seção é apresentada a tipologia resultante da análise aqui proposta.

6 De forma geral, pode-se afirmar que a fragmentação de um produto está associada aos custos de transporte e logística, do número de componentes do produto e do custo relativo de produção. 


\section{Economias segundo intensidade de $P \& D$ e performance comercial}

Empregando a metodologia delineada na seção metodológica, foi possível identificar a existência de quatro grupos de países (Quadro 1).

QUADRO 1

Classificação dos países selecionados, segundo nível tecnológico e comércio exterior em setores de alta tecnologia

\begin{tabular}{|c|c|c|}
\hline \multirow{2}{*}{$\begin{array}{l}\text { Intensidade } \\
\text { tecnológica }\end{array}$} & \multicolumn{2}{|c|}{ Saldo comercial } \\
\hline & Superávit & Déficit \\
\hline Alta & $\begin{array}{l}\text { Japão, Alemanha, França, } \\
\text { Suécia e Holanda (Grupo 1) }\end{array}$ & $\begin{array}{c}\text { Estados Unidos, Reino } \\
\text { Unido e Canadá (Grupo 2) }\end{array}$ \\
\hline Baixa & $\begin{array}{c}\text { China, Coreia, México, } \\
\text { Cingapura e Irlanda (Grupo 3) }\end{array}$ & $\begin{array}{c}\text { Itália, Brasil e } \\
\text { Espanha (Grupo 4) }\end{array}$ \\
\hline
\end{tabular}

Fonte: Elaboração própria.

O grupo 1, composto pelos líderes tecnológicos superavitários (Japão, Alemanha, França, Suécia e Holanda), é formado por países desenvolvidos com alta capacitação tecnológica e, em que pese o significativo consumo interno de produtos de alta tecnologia, que está obviamente associado às altas rendas per capitas, observam-se robustos saldos comerciais nestes setores. Estes saldos positivos derivam de históricas políticas industriais que lograram êxito em manter internalizadas as atividades industriais de alta tecnologia. Notadamente, estes países também sofrem pressōes para fragmentar sua produção e, por isso, certas atividades menos nobres, tais como a montagem final, acabam sendo deslocadas para países de salários médios relativamente inferiores.

Nesse sentido, estes países possuem robustos sistemas de inovação e ainda mantêm internalizada boa parte da manufatura, principalmente porque se especializaram, ao longo de sua história, em determinados segmentos produtivos. De fato, o surgimento dos setores de alta tecnologia, tal como aqui considerados, confunde-se com o desenvolvimento econômico destes países (FREEMAN; SOETE, 2008). A presença de atividades industriais de alta tecnologia deve-se, então, ao histórico esforço científico/tecnológico e à presença de políticas industriais efetivas de forte interferência estatal.

Muito embora também sofram influência das estratégias de fragmentação, os países que fazem parte do grupo 1 realizam etapas tanto tecnologicamente mais complexas como de maior intensidade de mão de obra. 
No grupo 1, talvez o exemplo mais paradigmático seja o da economia alemã, cuja histórica especialização nos complexos eletro-metal-mecânico e químico impacta positivamente os saldos comerciais dos setores aeroespacial, farmacêutico e de instrumentos de precisão. Essa histórica especialização deve-se, por sua vez, ao pioneirismo no estabelecimento de um sistema universal de ensino, inclusive técnico, que culmina com a criação do moderno conceito de universidade (ensino, pesquisa e extensão). Também contribui para o superávit comercial alemão a robusta política de comércio exterior centrada, sobretudo, nas economias nacionais que compõem a União Europeia, mas que, em se tratando das especializaçôes setoriais mais acentuadas, quase sempre transcende as relaçôes com este bloco de países (KECK, 1993; BRAGA, 1999; GOMES, 2006; OSÓRIO, 2010; STEHNKEN, 2010).

Outra característica relevante da economia alemã está associada ao forte e eficiente estímulo à criação e manutenção do emprego. De fato, ações que tentam garantir o emprego industrial tendem a contrabalancear os estímulos fragmentantes da produção (WEVER, 2005).

Não obstante, algumas atividades industriais - notadamente aquelas de maior propensão a se fragmentar, como, por exemplo, eletrônicos e informática - são deficitárias, pois escapam das políticas industriais e são alimentadas por forte demanda interna.

No caso alemão, tem-se então uma indústria de alta tecnologia competitiva e de forte base nacional. As tendências a fragmentar a produção, apesar de existirem, são contrabalanceadas pelo forte compromisso da política industrial em gerar e preservar empregos, bem como pela proteção alfandegária oferecida pela participação na União Europeia.

No grupo 2, formado pelos líderes tecnológicos deficitários, estão países cujas indústrias de alta tecnologia também estão entre as mais tecnologicamente sofisticadas do mundo, como Estados Unidos, Reino Unido e Canadá. Os países desse grupo possuem alta intensidade tecnológica, mas são deficitários no comércio de mercadorias de alta tecnologia. Sua produção de alta tecnologia está associada também à presença de mercados sofisticados e à histórica liderança científico-tecnológica mundial.

Tal como já mencionado, a existência desse grupo não era prevista pelas teorias mais tradicionais do comércio exterior, ou seja, a liderança tecnológica em setores de alta complexidade, num passado recente, era suficiente para garantir superávit nestes setores. Contudo, a fragmentação da produção forçou alterações nessa dinâmica.

Assim como no grupo 1, a presença de atividades industriais de alta tecnologia nos países do grupo 2 deve-se ao histórico esforço científico/tecnológico e ao pioneirismo no estabelecimento do que hoje se convencionou a chamar de alta tecnologia. 
Especificamente no grupo 2, é representativo o caso do complexo eletrônico, que é hoje o mais relevante da alta tecnologia e que surgiu no pós-guerra, associado, principalmente, aos esforços inovativos estadunidenses (FREEMAN; SOETE, 2008 e MOWERY; ROSENBERG, 2005).

Contudo, diferentemente do grupo 1, os países do grupo 2, apesar da presença de um alto nível de capacitação tecnológica nacional, apresentam expressivos déficits comerciais em setores de alta tecnologia. Estes déficits estão relacionados ao grande consumo interno e à menor efetividade das políticas industriais, que, embora existentes, não têm conseguido - ou não têm se preocupado em - manter a produção internalizada.

$\mathrm{Na}$ moderna divisão internacional do trabalho, os países do grupo 2 se especializaram, principalmente, em etapas mais complexas da cadeia de valor, deslocando a maior parte das etapas intensivas em mão de obra para países de baixos custos médios. Como consequência dessas estratégias empresariais, os países deste grupo tornaram-se deficitários no comércio de alta tecnologia (LINDEN; KRAEMER; DEDRICK, 2007).

No grupo 2, obviamente, destaca-se a economia estadunidense. Sua conhecida liderança tecnológica foi construída ao longo de todo o século XX e pode ser observada, por exemplo, a partir dos gastos em P\&D, do volume de patentes triádicas e do número de empresas líderes nos setores de alta tecnologia (NSF, 2010).

A construção dessa liderança deve-se, em boa medida, à consolidação de um robusto complexo-industrial militar, que transferia tecnologia bélica para a produção civil. No contexto da indústria de alta tecnologia, tal como ela é hoje definida, destaca-se o esforço de guerra estadunidense, notadamente aquele associado à Segunda Grande Guerra, que culminou em diversos conjuntos de inovações, entre eles o da microeletrônica, dos fármacos e da energia nuclear (GUERRIERI; MILANA, 1995; FREEMAN; SOETE, 2008; MOWERY; ROSENBERG, 2005).

No entanto, a liderança tecnológica estadunidense, que foi base dos argumentos descritos na teoria do ciclo de vida do produto, gradativamente passou a depender de produção estrangeira. De fato, os estímulos para fragmentar a produção de alta tecnologia são um tanto intensos no caso dos EUA, uma vez que os custos de produção e, em especial, o salário médio da alta tecnologia neste país são muito superiores daqueles observados, por exemplo, na China, segundo maior exportador de alta tecnologia do mundo (OECD.Stat; NSF, 2010). Ainda nesse contexto, a alta renda per capita estadunidense criou o maior mercado consumidor de alta tecnologia do mundo, estabelecendo, assim, forte pressão sobre a balança 
comercial. Por exemplo, o consumo aparente de alta tecnologia estadunidense em 2009 era de US\$ 799.141.799.649,00 frente a um consumo aparente chinês de US\$ 781.526.325.149 (OECD.Stat e MST).

Outro traço marcante e conhecido da economia estadunidense diz respeito ao forte estímulo às forças de mercado, que culmina em mercados altamente competitivos, nos quais as posições das firmas são constantemente ameaçadas. Como resultado, têm-se estratégias empresariais de aumento de produtividade mesmo em setores de alto risco e complexidade tecnológica.

A atuação conjunta de tais forças resulta em robustos déficits comerciais que persistem mesmo na presença de liderança tecnológica e grande volume de exportaçōes, principalmente dos setores aeroespacial e de informática. O fato é que o livre jogo das forças do mercado levou os Estados Unidos a uma situação na qual as estratégias competitivas das firmas estadunidenses - que são líderes mundiais - culminam em grande dependência externa de produção estrangeira, notadamente chinesa. Se em 2000 as importaçôes provenientes da China representavam 8,7\% das importaçôes totais estadunidenses, em 2011 esse valor passou a ser de 31\% (OECD.Stat).

O grupo 3 é formado por países com baixa intensidade tecnológica, mas com robustos superávits comerciais. Compõem este grupo países de renda per capita tanto alta como baixa, cujos representantes são China, Coreia, Cingapura, Irlanda e México. Assim como o grupo 2, este grupo não deveria existir segundo as teorias mais tradicionais em comércio exterior. Como será visto, sua presença ocorre apenas em razão do surgimento da fragmentação da produção.

Países classificados como seguidores tecnológicos superavitários possuem uma baixa capacitação tecnológica nacional, mas, em razão de políticas industriais ativas e de custos de produção internacionalmente competitivos, acabam exercendo forte poder de atração de atividades fragmentadas, destinadas, quase sempre, à exportação. Assim, em que pesem os crescentes mercados internos, a presença de alta tecnologia explica-se no grupo 3, sobretudo, pela inserção nas cadeias produtivas globais fragmentadas.

Mesmo tendo, atualmente, intensidades tecnológicas abaixo da média mundial, os países do grupo 3, no qual predominam os do leste asiático, parecem encontrar-se em processos de convergência tecnológica, muito embora os níveis de convergência variem significativamente entre os membros do grupo.

A presença de políticas industriais efetivas que visam tanto atrair atividades industriais quanto estimular aquelas já existentes é o traço distintivo do grupo 3 diante do conjunto dos países deficitários. A realização de superávit é, então, fruto 
do emprego histórico de política industrial bem-sucedida e de salários atrativos (isso é particularmente válido para o leste asiático).

$\mathrm{Na}$ divisão do trabalho aqui proposta, o grupo 3 encarrega-se da realização de etapas de maior intensidade de mão de obra, em sua grande parte destinada a mercados estrangeiros de alta renda per capita. Contudo, à medida que as rendas per capitas dos países deste grupo se elevam, o consumo interno também passa a constituir elemento relevante à localização da produção.

Mesmo que os casos irlandês e mexicano sejam relevantes, é no leste asiático, mais especificamente na China, que se encontram os elementos característicos do grupo 3.7 $\mathrm{O}$ processo de desenvolvimento tecnológico da periferia, que parece ter acontecido mais fortemente no leste asiático, possui três momentos distintos. $\mathrm{O}$ primeiro está associado à convergência japonesa, que ocorreu ao longo das décadas de 1950 e 1960. O segundo associa-se à emergência dos Tigres Asiáticos, ${ }^{8}$ representada pelos níveis de renda per capita próximos de países desenvolvidos. Por fim, o último momento, ainda em curso, diz respeito à ascensão econômica da China, que, desde inícios da década de 1990, tornou-se hegemônica nas exportações de manufaturados na Ásia (KIM, 1993, 2005; HOU; GREE, 1993; STURGEON, 2002; LALL; ALBALADEJO;e ZHANG, 2004; LALL, 2005; HOBDAY, 2005; LEE, 2005; LALL; WEISS; ZHANG, 2005; SRHOLEC, 2007; DICKEN, 2007).

Os indicadores chineses de ciência, tecnologia e inovação apresentaram, ao longo da última década do século XX e da primeira do século XXI, um crescimento significativo. De fato, a intensidade de P\&D em relação ao PIB nacional cresceu quase um ponto percentual entre 1991 e 2006 (0,8\% a 1,4\%), levando a um crescimento ainda maior nas publicações científicas indexadas e nas patentes triádicas da China (MST, 2007).

Não obstante, o crescimento da capacidade científica e tecnológica da China ainda não a permitiu inserir-se no conjunto de líderes tecnológicos. Os indicadores de produção e consumo, assim como os de C,T\&I, também apresentaram elevado percentual de crescimento. Assim, em 2007, dos países analisados neste trabalho, a China ocupava a segunda colocação em produção, consumo e exportação de alta tecnologia, sendo que as variáveis de consumo e exportação apresentaram um crescimento nominal no período 1995-2007 de mais de 800\% (NSF, 2010). Boa

\footnotetext{
7 Por outro lado, o México é um caso especial, uma vez que sua proximidade geográfica com os Estados Unidos, bem como seus custos de produção inferiores, acabam exercendo forte atração de certas atividades de alta tecnologia. Mesmo assim, as atividades de alta tecnologia executadas pelas maquiladoras mexicanas caracterizam-se pela baixa agregação de valor e alto coeficiente importado (PALMA, 2005).

8 Coréia do Sul, Cingapura, Taiwan e Hong Kong.
} 
parte da produção deve-se a um crescente investimento externo direto que em 2009, segundo dados da UNCTAD (UNCTADstat.), aproxima-se de US\$ 1 trilhão (nove vezes o IDE recebido pela Coreia, por exemplo).

No entanto, e por mais que estes números permitam falar num processo de convergência, com base nos dados atualmente disponíveis, pode-se afirmar que a China não se encontra entre os líderes tecnológicos mundiais, uma vez que seus gastos em P\&D, quando comparados com outros países produtores de alta tecnologia, ainda são baixos e aparentemente dependentes de tecnologia estrangeira e seu esforço inovativo está concentrado em inovações de processos, quase sempre, de caráter incremental.

Por outro lado, custos de produção inferiores e mão de obra barata e relativamente qualificada (resultado de uma deliberada política nacional de capacitação) exercem forte poder de atração de atividades de manufatura de determinados componentes e de montagem final. Esse poder de atração é alimentado também pela participação do Estado, que tanto direciona a economia para a captação de investimento direto externo quanto realiza ele mesmo forte investimento em tecnologia industrial básica, principalmente infraestrutura (FAN; WANG, 2010; TAN, 2002).

Destaca-se ainda, no exemplo chinês, o crescimento da renda per capita nos últimos anos, que acabou por criar um importante mercado interno de produtos de alta tecnologia (NSF, 2010). É razoável supor, contudo, que boa parte do vasto mercado interno chinês de produtos de alta tecnologia esteja associada ao consumo intermediário destinado às exportações. Mesmo assim, não se pode negar a emergência de um mercado interno de produtos classificados como de alta tecnologia naquele país.

Em que pesem o aumento da renda per capita, que culmina num crescente mercado interno, e a forte dependência externa de tecnologia, a China acaba por se tornar uma economia superavitária em termos de alta tecnologia. De fato, o superávit chinês é o terceiro maior do mundo nestes setores (OECD.Stat.).

Finalmente, o grupo 4 engloba os países seguidores tecnológicos deficitários, cujos saldos comerciais de alta tecnologia são deficitários e as intensidades tecnológicas baixas. Fazem parte deste grupo 4 Itália, Espanha e Brasil, portanto, tanto países de alta como de baixa renda per capita. A debilidade das políticas industriais e a passividade com que os sistemas nacionais de inovação lidam com a geração de tecnologia caracterizam, de forma geral, este grupo de países.

Pertencem ao grupo 4 as economias nacionais que, apesar de possuírem alguma produção de alta tecnologia, não têm sido hábeis no seu desenvolvimento diante das cadeias produtivas globais. De fato, as atividades de alta tecnologia destes países são altamente dependentes de fontes externas de tecnologia e pouco se articulam 
com seus tecidos industriais. Essas atividades acabam se restringindo à realização da montagem final e destinam-se, quase sempre, aos respectivos mercados internos (ALBUQUERQUE, 1999; FURTADO; CARVALHO, 2005; ARRUDA; VERMULM; HOLLANDA, 2006; CARNEIRO. 2008). Pode-se especular, inclusive, que, caso não houvesse possibilidade de fragmentar a produção, no contexto de economias abertas, não existiria qualquer atividade de alta tecnologia em tais países. Ou seja, os mercados internos, apesar de consideráveis, seriam quase que totalmente supridos por importações.

O Brasil faz parte deste grupo, que é representativo da situação de muitas economias latino-americanas e de outros países em desenvolvimento. Por outro lado, estão presentes no grupo 4 economias europeias, que, apesar da alta renda per capita, possuem dificuldades em articular suas instituiçóes científicas com as demandas produtivas da indústria. De fato, estas economias europeias, assim como as latino-americanas, carecem de sistemas de inovação articulados e eficientes que as possam permitir internalizar atividades produtivas de alta tecnologia na mesma medida em que demandam produtos desta indústria.

$\mathrm{Na}$ divisão internacional do trabalho, o grupo 4 desempenha papel marginal e se encarrega de realizar a montagem final destinada ao próprio consumo interno. A economia que melhor representa este grupo e por isso melhor o ilustra é a brasileira.

Alburque (1999) classifica o sistema brasileiro de inovação como velho e ineficiente. Suzigan e Furtado (2010) afirmam que as políticas tecnológicas e industriais no Brasil são ineficazes, sendo executadas a partir de uma estrutura institucional rígida, envelhecida e com sobreposições de funções. Ou seja, por mais que existam esforços de desenvolvimento científico e tecnológico, estes alcançam poucos êxitos. De fato, a intensidade tecnológica da alta tecnologia brasileira é uma das menores do conjunto de países apresentado na Tabela 1 (muito embora seja superior, por exemplo, à chinesa).

Corroborando este quadro de dependência tecnológica externa da economia brasileira, têm-se um baixo número de formados em áreas tecnológicas (engenharias, ciências, etc.), um errático investimento público em infraestrutura, ciência e tecnologia e uma mão de obra de baixa produtividade9 (INEP, 2008; GIAMBIAGI, 2004; IBGE), fatos estes que diminuem significativamente a atratividade do país.

No Brasil, observa-se um importante consumo interno de produtos de alta tecnologia. Apesar de existir algum consumo intermediário, notadamente ligado às poucas atividades de montagem final, é razoável supor que o consumo final seja

9 Enquanto nos Estados Unidos um trabalhador adiciona, em média, US\$170 mil/ano, no Brasil, um trabalhador adiciona apenas US\$ 57 mil/ano, valor inferior, por exemplo, ao observado na China, na Coreia e em Cingapura (OECD.Stat, IBGE, NBSC, Inegi, Singstat). 
mais significativo neste caso, principalmente quando se considera o crescimento da economia nos últimos anos da década de 2000. Como resultado têm-se, além da forte dependência tecnológica externa, crônicos e históricos déficits de alta tecnologia, que só são diminuídos em razão do sucesso comercial da montagem de aeronaves de porte regional no Brasil.

Portanto, a atuação conjunta destes elementos faz do Brasil um exemplo paradigmático do grupo de países seguidores tecnológicos deficitários, os quais se encontram à margem dos grandes fluxos comerciais de alta tecnologia.

Considerando-se as discussões realizadas e, principalmente, o comportamento dos casos particulares aqui estudados - Alemanha, Estados Unidos, China e Brasil -, bem como a forma como estes se inserem na moderna divisão do trabalho, questiona-se como é possível existirem líderes tecnológicos deficitários e seguidores tecnológicos superavitários?

Como se viu, essa aparente incongruência deve-se a uma nova forma de organizar as cadeias produtivas globais. Nessa nova organização, o processo produtivo de um mesmo produto de alta tecnologia pode ser segmentado em diferentes partes e deslocado em distintos países de acordo com a atratividade local e com as demandas do processo produtivo.

Assim, se, no passado, a produção de produtos tecnologicamente complexos só ocorria em países que fossem capazes de realizar seu desenvolvimento tecnológico, agora é possível separar espacialmente a produção do desenvolvimento. Obviamente, por se tratar de alta tecnologia, alguma capacitação tecnológica nacional é exigida, mesmo para a execução de etapas menos complexas da produção. $O$ fato essencial diz respeito à possibilidade de se produzir alta tecnologia mesmo na ausência de mercados consumidores locais e/ou alta capacitação tecnológica. E é nisto que a presente análise se distingue das teorias anteriores vinculadas ao ciclo de vida do produto.

Este atual padrão de produção resulta numa nova divisão do trabalho, na qual países líderes tecnológicos podem se tornar deficitários, principalmente quando os volumes consumidos internamente são substanciais. Por outro lado, países seguidores tecnológicos podem, quando seu consumo interno permitir, se tornar superavitários, mesmo em atividades de alta tecnologia. A política industrial, tanto para atrair etapas do processo produtivo quanto para manter aquelas já existentes, é, então, o fiel da balança comercial.

Levando-se em conta a antiga divisão do trabalho proposta por Vernon (1966), Hircsh (1967), Wells (1968) e Dosi, Pavitt e Soete (1990), a discussão aqui apresentada agrega a ela dois novos grupos de países: líderes tecnológicos deficitários e seguidores tecnológicos superavitários. 
Tanto pelo volume transacionado quanto pela rapidez com que se processa a mudança espacial, a agregação destes dois grupos deve-se, em boa medida, ao relacionamento entre Estados Unidos e China. De fato, pode-se afirmar que as relações comerciais entre estes dois países são paradigmáticas da nova divisão internacional do trabalho em alta tecnologia.

Por exemplo, em 2011, o déficit comercial estadunidense em relação à China (-US\$ 128 bilhões) era o maior entre todos os países com os quais os Estados Unidos realizam negócios. Também em 2011, cerca de um terço das importações de alta tecnologia realizadas pela economia mais rica do mundo (EUA) provinha de um país cuja renda per capita, em 2011, não ultrapassava US\$ 5.000/ano.

Quando se observa a participação das importaçôes de alta tecnologia provenientes da China no consumo aparente dos Estados Unidos, a constatação de que a produção estadunidense tem se deslocado para a China fica ainda mais evidente. Num período de sete anos, a participação das importaçóes chinesas no consumo aparente estadunidense de produtos de alta tecnologia mais do que quadruplicou, saltando de aproximadamente 3\%, em 2000, para 13\%, em 2009 (OECD.Stat.). Notadamente, a explicação para tal fenômeno encontra-se no interior da dinâmica de fragmentação da produção.

\section{Considerações finais}

Ao analisar as intensidades tecnológicas e os saldos comerciais do setor de alta tecnologia das principais economias produtoras mundiais, este trabalho encontrou duas situações não previstas pelas formulaçôes mais tradicionais da economia internacional. Mesmo abordagens mais heterodoxas do comércio exterior, tal como a evolucionista, ao não prever a separação física da produção de um bem tecnologicamente complexo, falham na observação da atual dinâmica. Estas duas situaçôes dizem respeito à existência de países líderes tecnológicos deficitários e países seguidores tecnológicos superavitários.

Para explicar a existência destes dois grupos, é preciso incorporar a tais teorizaçōes tradicionais - tanto ortodoxas quanto heterodoxas - a perspectiva da fragmentação da produção, que, ao separar geração de tecnologia e manufatura, levou a uma reordenação das cadeias produtivas globais de alta tecnologia. Nesse sentido, esses dois fenômenos representam não anomalias num sistema conhecido, mas sim um novo sistema com mecânica própria.

Quando se observa, por exemplo, o trabalho de Lall (2005), pode-se especular que este é um movimento ainda em curso e que os países asiáticos tendem a migrar para categoriais tecnologicamente superiores (tal como fez o Japão). De fato, o jogo 
de forças que atua na dinâmica comercial da alta tecnologia pode ainda ser muito mais intenso, transformando completamente a tipologia e levando, por exemplo, líderes a se tornarem seguidores ou superavitários em deficitários.

Seja como for, a tipologia aqui apresentada tem o mérito de apontar a existência de dinâmicas não tradicionais e ainda pouco observadas no agregado. Se este é apenas um momento de um processo ainda em curso, essa é outra questão, cuja resposta dependerá do transcorrer dos anos, de um profundo esforço de análise e, obviamente, de um outro trabalho.

\section{Referências bibliográficas}

ALBUQUERQUE, E. National systems of innovation and non-OECD countries: notes about a rudimentary and tentative "typology". Revista Brasileira de Economia Política, v. 19, n. 4(76), 1999.

ARRUDA, M.; VERMULM, R.; HOLLANDA, S. Inovação tecnológica no Brasil: a indústria em busca de competitividade global. São Paulo: Anpei, 2006.

BRAGA, J. C. de S. Alemanha: império, barbárie e capitalismo avançado. In: FIORI, J. L. (Org.). Estados e moedas no desenvolvimento das naçōes. Petrópolis: Ed. Vozes, 1999.

CARNEIRO, R. Impasses do desenvolvimento: a questão produtiva. Campinas: IE/Unicamp, 2008 (Texto para discussão, n. 153).

CASTELLS, M. A sociedade em rede. São Paulo: Paz e Terra, 1999.

CHESNAIS, F. A mundialização do capital. São Paulo: Xamã, 1996.

COMTRADE. United Nations Commodity Trade Statistics Database. Disponível em: <http:// comtrade.un.org/db/>. Acesso em: 10 fev. 2013.

DEDRICK, J.; KRAEMER, K. Personal computing, innovation in global industries. Washington, DC: National Academy Press, 2008.

DICKEN, P. Global Shift. 5.ed. New York: Guilford Press, 2007.

DOSI, G.; PAVITT, K; SOETE, L. The economics of technological change and international trade. Brighton: Wheatshaf, 1990.

FAN, G.; WANG, X. China towards 2020: growth performance and sustainability. In: OCDE. Growth and sustainability in Brazil, China, Indonesia and South Africa. Paris, 2010.

ERNST, D.; KIM, L. Global production networks, knowledge diffusion, and local capability formation. Research Policy, n. 31, p. 1417-1429, 2002. 
FREEMAN, C.; SOETE, L. A economia da inovação industrial. Campinas: Editora Unicamp, 2008 (Clássicos da Inovação).

FURTADO, A. T.; CARVAlHO, R. Q. Padrões de intensidade tecnológica da indústria brasileira: um estudo comparativo com países centrais. In: KON, A. Indústria, trabalho e tecnologia: subsídios à política pública. São Paulo: EITT/PUC-SP, 2005.

GIAMBIAGI, F. A politica fiscal do governo Lula: qual é o limite para o aumento do gasto público? Rio de Janeiro: Ipea, 2004.

GOMES, F. Conflito social e welfare state: Estado e desenvolvimento social no Brasil. RAP, v. 40, n. 2, p. 201-236, 2006.

GUERRIERI, P.; MILANA, C. Changes and trends in the world trade in high technology products. Cambridge Journal of Economics, v. 19, n. 1, p. 225-242, February 1995.

HIRSCH, S. Location of industry and international competitiveness. Oxford: Clarendon Press, 1967.

HIRSCH-KREINSEN, H. "Low-tech" innovations. Industry \& innovation, v. 15, n. 1, p.19-43, 2008.

HIRSCH-KREISEN, H. et al. Low-tech industries and knowledge economy: state of the art and research challenges. Oslo: Pilot Projetc, 2003.

HOBDAY, M. Os sistemas de inovação do leste e do sudeste asiático: comparações entre o crescimento do setor eletrônico promovido pelo sistema FEO e pelas ETNS. In: KIM, L.; NELSON, R. (Eds.). Tecnologia, aprendizado e inovação: as experiências das economias de industrialização recente. Campinas: Editora Unicamp, 2005 (Clássicos da Inovação).

HOBSBAWM, E. Era dos extremos: o breve século XX. São Paulo: Companhia das Letras, 1995.

HOU, C.; GREE, S. National systems supporting technical advance in industry: the case of Taiwan. In: NELSON, R. (Ed.). National innovation systems: a comparative analysis. Oxford University Press, 1993.

HUMPHREY, J.; SCHMITZ, H, Governance in global value chains. IDS Bulletin, v. 32, p. 19-23, 2002.

IBGE. Sistema IBGE de Recuperação Automática. Disponível em: <http://www.sidra.ibge.gov.br/>.

INEGI. Banco de Información Económica. Disponível em: <http://dgcnesyp.inegi.org.mx/ cgi-win/bdieintsi.exe/NIVR250090\#ARBOL>. Acesso em: 20 jul. 2011.

Indicadores sobre actividades científicas e tecnológicas. Disponível em: <http:// www.inegi.org.mx/inegi/default.aspx?s=est\&c=126>. Acesso em: 20 jul. 2011. 
INEP. Censo da Educação Superior. 2008. Disponível em: <http://www.inep.gov.br/superior/ censosuperior/default.asp>. Acesso em: 21 out. 2011.

KECK, O. The national system for technological innovation in Germany. In: NELSON, R. (Ed.). National innovation systems: a comparative analysis. Oxford University Press, 1993.

KIM, L. National system of industrial technology in a developing country: a model. In: NELSON, R. (Ed.). National innovation systems: a comparative analysis. Oxford University Press, 1993.

. O sistema de inovação sul-coreano em transição. In: KIM, L.; NELSON, R. (Eds.). Tecnologia, aprendizado e inovação: as experiências das economias de industrialização recente. Campinas: Editora Unicamp, 2005 (Clássicos da Inovação).

KRUGMAN, P. Increasing returns and economic geography. Journal of Political Economy, n. 99, 1991.

LALL, S. A mudança tecnológica e a industrialização nas economias de industrialização recente da Ásia: conquistas e desafios. In: KIM, L.; NELSON, R. (Eds.) Tecnologia, aprendizado $e$ inovação: as experiências das economias de industrialização recente. Campinas: Editora Unicamp, 2005 (Clássicos da Inovação).

LALL, S.; ALBALADEJO, M.; ZHANG, J. Mapping fragmentation: electronics and automobiles in East Asia and Latin America. QEH, 2004 (Working paper series, n. 115).

LALL, S.; WEISS, J.; ZHANG, J. The 'sophistication' of exports: a new measure of products characteristics. QEH, 2005 (Working paper series, n. 123).

LEE, K. O aprendizado tecnológico e o ingresso de empresas usuárias de bens de capital na Coréia do Sul. In: KIM, L.; NELSON, R. (Eds.). Tecnologia, aprendizado e inovação: as experiências das economias de industrialização recente. Campinas: Editora Unicamp, 2005 (Clássicos da Inovação).

LINDEN, G.; KRAEMER, K.; DEDRICK, J. Who captures value in a global innovation system? The case of Apple's Ipod. Personal Computer Industry Center, Jun. 2007.

MACHER, J. T.; MOWERY, D. C. (Eds.). Innovation in global industries: U.S. firms competing in a new world. Board on Science, Technology, and Economic Policy (STEP). Washington DC: The National Academies Press, 2008. Disponível em: <http://books.nap. edu/openbook.php? record_id=12112\&page=R1>.

MOWERY, D.; ROSENBERG, N. Trajetórias da inovação: a mudança técnica nos Estados Unidos da América no século XX. Campinas: Editora Unicamp, 2005 (Clássicos da Inovação).

MST. Science and Technology Statistics Year Book. 2007. Disponível em: <http://www.most. cn/eng/statistics/2007/index.htm>. Acesso em: 02 ago. 2013. 
NBSC. China Statistical Year Book. 2007. Disponivel em: <http://www.stats.gov.cn/tjsj/ ndsj/2007/indexeh.htm>. Acesso em: 01 out. 2011.

NELSON, R.; ROSENBERG, N. (Eds.). National innovation systems: a comparative analysis. Oxford University Press, 1993.

NSF. Science and engineering indicators, 2010. Disponível em: <http://www.nsf.gov/statistics/ seind10/appendix.htm>. Acesso em: 01 out. 2011.

OCDE. Frascati manual: proposed standard practice for surveys on research and experimental development. Paris, 2002.

OECD.STATS. Disponível em: <http://stats.oecd.org/Index.aspx>. Acesso em: 10 maio 2013.

OHLIN, B. Interregional and international trade. Cambridge: Harvard University Press, 1933.

OSÓRIO, L. O dilema alemão no sistema interestatal capitalista contemporâneo. In: XIV Encontro Regional da ANPUH-RIO. Anais..., 2010.

PALMA, G. Gansos voadores e patos vulneráveis: a diferença da liderança do Japão e dos Estados Unidos no desenvolvimento do sudeste asiático e da América Latina. In: FIORI, J. (Ed.). O poder americano. 2. ed. Petrópolis: Vozes, 2005.

PAVITT, K. Sectoral patterns of technical change: towards a taxonomy and a theory. Research Policy, n. 13, p. 343-373, 1984.

PORTER, M. Competition in global industries. Cambridge: Harvard Business School Press, 1986.

RICARDO, D. Princípios de economia política e tributação. São Paulo: Nova Cultural, 1996 (1817) (Coleção Os economistas).

SINGSTAT. Key annual indicators. Disponível em: <http://www.singstat.gov.sg/stats/stats. html>. Acesso em: 10 maio 2013.

SMITH, K. Industrial structure, technology intensity and growth: issues for policy. In: DRUID CONFERENCE, 1999.

What is the 'knowledge economy'? Knowledge-intensive industries and distributed knowledge bases. In: DRUID CONFERENCE, 2000.

SRHOLEC, M. High-tech exports from development countries: a symptom of technology spurts or statistical illusion? Oslo: Kiel Institute, 2007.

STEHNKEN, T. The German innovation system at a glance: governance and strategies. In: Workshop Innovation and Opportunities for Cooperative Projects Brazil - Germany. Rio de Janeiro, Inmetro, ABDI e FHG, ago. 2010. 30 slides. 
STURGEON, T. Modular production networks: a new American model of industrial organization. MIT, 2002 (Working paper IPC-02-003).

SUZIGAN, W.; FURTADO, J. Instituições e políticas industriais e tecnológicas: reflexões a partir da experiência brasileira. Est. econ., v. 40, n. 1, p. 7-41, jan./mar. 2010.

TAN, Z. Product cycle theory and telecommunications industry - foreign direct investment, government policy, and indigenous manufacturing in China. Telecommunications Policy, n. 26, 2002.

UNCATDstats. Disponível em: <http://unctadstat.unctad.org/UnctadStatMetadata/Documentation/AboutUNCTADstat.html> Acesso em: 05 ago. 2013.

VERNON, R. International investment and international trade in the product life cycle. Quartely Journal of Economics, n. 80, p. 190-207, 1966.

WELLS, L. A product life cycle for international trade. Journal of Marketing, v. 32, p. 1-6, 1968.

WEVER, K. Negotiating competitiveness: employment relations and organizational innovation in Germany and the United States. Harvard Business Scholl Press, 1995.

ZEITOUM, C. Novas funçôes e acumulo de competências nas empresas prestadoras de serviços por contrato: um estudo a partir do caso da FLEXTRONICS. Dissertação (Mestrado em Política Científica e Tecnológica). Instituto de Geociências, Universidade Estadual de Campinas, Campinas, 2009. 